\title{
The Use of Discourse Markers in E.F.L. Learners' Writing
}

\author{
Ana Cristina Lahuerta Martínez \\ University of Oviedo \\ lahuerta@correo.uniovi.es
}

\begin{abstract}
This study investigates the use of discourse markers by Spanish learners of English. It is intended as an initial contribution to the study of how discourse markers are used by foreign language learners. We conduct two pilot studies involving the use of English discourse markers by native speakers of Spanish. We first study if these speakers use English discourse markers at all in their writings and if they use some markers and not others. We then compare the use they make of discourse markers in Spanish and in English. This study shows that native speakers of Spanish use discourse markers extensively and in appropriate ways both in Spanish and in English. We also observe some differences between the writings in English and Spanish with respect to the number of markers employed as well as the variety of markers used. With these initial results, we intend to better define future research questions and directions.
\end{abstract}

\section{Introduction}

Within the past fifteen years or so there has been an increasing interest in the theoretical status of discourse markers (henceforth DMs), focusing on what they are, what they mean and what functions they manifest. In order to understand the function of DMs in language we will refer to the relevance-theoretic approach to $\mathrm{DMs}^{1}$ 


\section{Relevance theory}

Until recently communication was seen as a process of codification and decodification of utterances. However, since Grice (1975), communication is perceived in a different way. It does not constitute exclusively a codification process but also, and mainly, an inference labour. The speaker tries to make the hearer reach a series of inferences through the interaction of the utterance with the context. When I say I am cold, I not only want my interlocutor to understand my utterance, but I also want him to understand that I want to close the window. From this approach, we can say that one of the functions of DMs consists of facilitating inferences that want to be communicated. ${ }^{2}$

Sperber and Wilson (1986/1995) have developed a theory, the Relevance Theory, based on Grice. This is a pragmatic model that attempts to explain how speakers interpret utterances. It is based on a hypothesis of a cognitive nature about how human beings process linguistic information. This hypothesis suggests that the mind's central processor is highly effective in handling the information because it is specifically oriented towards the search for relevance.

The Principle of Relevance entitles the addressee to assume that an utterance comes with a guarantee of its own optimal relevance. An interpretation is considered to be consistent with the presumption of optimal relevance if the speaker could rationally have intended to be optimally relevant to the hearer on that interpretation. The presumption of optimal relevance entitles the addressee to expect a level of relevance which is high enough to justify attending to the stimulus, and which is the highest level of relevance the communicator was capable of achieving given his or her means and goals. Having accessed an interpretation consistent with the presumption of optimal relevance, the hearer takes that to be the intended interpretation.

On Sperber and Wilson (1986/1995)'s view, utterance interpretation involves decoding and inference. Decoding leaves the hearer with an incomplete (i.e. not fully propositional) conceptual representation. In order to arrive at a fully propositional representation, the hearer has to inferentially enrich the incomplete representation. This inference is basically a process of hypothesis formation and confirmation. Relevance is the criterion for testing the hypotheses. Other things being equal, the hearer will choose an optimally relevant interpretation. According to Sperber \& Wilson (1995: 270) an utterance is optimally relevant iff (a) it achieves sufficient contextual effects to be worth the hearer's processing effort and (b) it is the most relevant one the speaker could have produced given her abilities and preferences.

Probably one of the most important contributions of the Relevance theory to linguistic research is the review and redefinition of the concept of context. For Sperber and Wilson, context includes not only the information about the immediate physical environment (physical context), or about previous utterances (linguistic context or co-text), but also a set of assumptions stored in memory and deductively accessible, which participate in the interpretation of an utterance as well. These assumptions are made up of information of all 
kinds: beliefs, cultural knowledge, sociolinguistic competence, daily experience, encyclopaedic knowledge of the world, etc.

There are three basic ways in which information provided by an utterance can combine with the context. Firstly, it may combine with existing assumptions to yield a contextual implication. Secondly, new information can strengthen an existing assumption of the hearer's. Finally, new information can contradict and eliminate one (or, indeed, more) of the hearer's existing assumptions.

\subsection{Relevance theory and discourse markers}

In the 70 s and 80 s text linguistics focused on the grammatical elements that appear in utterances connecting sentences and, in general, textual sequences (see, especially, Halliday and Hasan, 1976). From this theoretical perspective, the presence of connective sequences is closely related to the properties of cohesion and coherence, considered the defining characteristics of the text; in this way, connection is considered one of the cohesive procedures of text (together with reference, ellipsis and lexical cohesion) and is regarded as the mechanism that specifies the particular semantic relation obtaining between two sentences. However, later studies have revealed the inaccuracy of this analysis of discourse markers as providing cohesion. Thus, it must be pointed out that, on the one hand, the lack of this type of connective device does not necessarily imply the disappearance of the conjunctive relation they express, and, therefore, the global utterance formed by two propositions related without a connective may be perfectly coherent.

On the other hand, the presence of a connective does not guarantee the interpretability of the resulting utterance, as the following example shows:

(1) He is French; however, he is a pilot

Although we understand the conceptual meaning of the propositions employed, as well as the contrasting value of the connective however, it is difficult to interpret this utterance as a whole, since we do not see in which sense being French is in contrast with being a pilot.

In sum, the interpretation of a text or utterance does not depend on the cohesive devices it contains, therefore cohesion is not a necessary condition for the communicative effectiveness of a text or utterance (cf. Blass, 1990).

With respect to the second distinctive characteristic of texts, coherence, as Blakemore (1987) points out, even if the text contains formal mechanisms that manifest its internal coherence - for example, discourse connectives-, it is possible that such connective devices may not be established among explicit elements of the text, but may indicate a relationship between a proposition conveyed by an actual utterance and a proposition that has not been linguistically realised. The hearer has to use the discourse connective to access implicit assumptions only accessible in the cognitive context and use them to process the utterance.

In sum, coherence relations are not necessary to account for utterance interpretation or textuality. The fundamental assumption of Sperber and Wilson's model is that what is 
communicated should not so much be related to previous information, that is, be coherent, but should be essentially relevant, that is, important and informative. Therefore, from a relevance-based perspective, an utterance that is not formally or semantically connected to a previous one may be relevant in a given context. As Blass (1990) states, what textual approaches based on coherence and cohesion lack is an adequate notion both of context, and the relation between text and context.

As we have already pointed out, Relevance Theory states that speakers interpret information searching for relevance. As the information carried by an utterance only has contextual effects if it is combined with the adequate assumptions existing in the mental representation of the world the hearer has stored in his memory, a crucial aspect of Sperber and Wilson's theory is how the appropriate context is selected and made accessible in each case. It is at this point where, according to Blakemore (1987), the expert in the study of DMs (she calls them discourse connectives) from a relevance-theoretic approach, connectives contribute essentially to the interpretation process. From this theoretical perspective, connectives are considered signals the speaker uses to guide cooperatively his hearer's interpretative process.

Blakemore (especially 1987, 1988, 1989a, 1989b, 1992 and 1993) considers that the essential function of elements like likewise, therefore, because, etc is to guide the hearer's interpretation process through the specification of certain properties of the context and the contextual effects; more specifically, these elements constrain the relevant context for the interpretation of an utterance, reinforcing some inferences or eliminating other possible ones and thus help process the information.

DMs, therefore, have a guiding meaning for inference in the interpretation process. Blakemore proposes that DMs do not have a representational meaning the way lexical expressions like boy and hypothesis do, but have only a procedural meaning, which consists of instructions about how to manipulate the conceptual representation of the utterance (cf. Blakemore, 1987, 1992). Words with conceptual meaning contribute to the content of assertions and are analysed as encoding elements of conceptual representations. Words with procedural meaning, on the other hand, encode information about how these representations are to be used in inference, they tell you how to 'take' these representations. In Blakemore's view, DMs do not contribute to the proposition expressed by an utterance or to any other conceptual representation the utterance may communicate; rather they point the hearer to the context in which he is expected to process the utterance and the conclusions he should be drawing from it.

The notion of procedural meaning is not unique to RT. As Wilson and Sperber (1993) point out the idea that some linguistic expressions do not encode concepts but indicate how to 'take' a host sentence or phrase is developed in the work of Ducrot and his associates (Ducrot, 1972, 1973, 1984; Anscombre and Ducrot, 1983). Roughly similar notions also surface in RT-influenced accounts of items referred to as DMs, for example in Hansen's claim that DMs lack a conceptual core and 'are basically instructions on how to process their host utterance in a given context' (Hansen, 1997:160). 
We can conclude this section by saying that the most relevant contribution of the Relevance Theory to the study of DMs is the semantic-pragmatic characterisation of these units as aids or instructions for interpretation - specifically, the facilitation of inferencesand, therefore, the definition of DMs as elements with procedural meaning.

\section{Research questions}

This study aims to analyse the use of DMs in written discourse by nonnative speakers of English. We conducted a pilot study involving the use of English discourse markers by native speakers of Spanish which will allow us to better define research questions and directions.

All languages make use of DMs or some such devices although the repertoire of devices and their various functions may vary from one language to another. As we have made clear in the previous sections, for relevance theorists DMs constrain the interpretation process by guiding the hearer towards the intended context and contextual effects. Therefore, DMs play a facilitating role.

Since DMs facilitate communication, it is logical to suppose that the lack of DMs in an L2, or their inappropriate use could, to a certain degree, hinder successful communication or lead to misunderstanding. L2 learners must learn to signal the relations of their utterances to those that precede and follow. Therefore, in terms of communicative competence, L2 learners must acquire the DMs of the L2. It is plausible to suppose that those nonnative speakers who are competent in the use of the DMs of the L2 will be more successful in interaction (oral and written) than those who are not.

We will study DMs in written discourse. ${ }^{3}$ It is not within the scope of this work to study the different uses of DMs in oral and written discourse; however, we want to point out that as DMs are a procedure of the language to facilitate the relationship between what is said and the context, different contexts (oral or written) will make a different use of these units.

\section{Pilot study I}

We started asking some initial question which we hoped could eventually be narrowed. First, we asked if the nonnative speakers use discourse markers at all and second, if they use some markers and not others. We set out to answer these initial questions by collecting natural language data. Seven people participated in this study. The seven participants of this study had studied English in high school and were taking a degree in English Language and Literature at the University of Oviedo. They had to write an essay on an applied linguistics topic (approaches and methods in language teaching, needs analysis, learning strategies, etc.) as part of the evaluation procedure of the subject Applied Linguistics.

We analysed the section conclusions of their papers (the length of this section was around 500 words). The analysis of the data proceeded in the following way. If there were 
discourse markers, then we determined the range of markers used by each participant. The use of discourse markers by the seven participants was then compared.

\subsection{Results}

The data revealed that discourse markers were used extensively by participants. They had no problems using markers in appropriate ways. However, the participants differed from each other in several important respects. Although all participants used some discourse markers, some participants employed a wider range of markers than others.

Consider some short excerpts from two of the participants, A and G, where discourse markers are in italics.

A: As I stated in the introduction of this essay the objectives of my study were to suggest ways to improve the teaching of speaking, writing, listening and reading. I have emphasised the idea that all these skills are closely interrelated in L2 learning and should be taught in an integrative way oriented towards successful use of the language. This will help learning and lesson planning and teachers will manage to get high benefits because the practice of skills is integrated and interrelated as it is in real life. The level of students should be a key element to organise class activities. Teachers should avoid mechanical and repetitive activities and elaborate interesting activities to develop their students' competence in the language.

G: In this essay I have carried out a case study of a learner of English as a foreign language to find out some information about the strategies she uses to learn a foreign language. In particular, I have been observing the case of a twenty-year-old Italian girl, whose motivation has enabled her to achieve a great improvement in her English over the sixteen months she has been living in London. Through an interview, I obtained information about her beliefs and also about her preferred strategies. On the one hand, I analysed her beliefs about the importance of English as a language. I found out that she believes English is one of the most important languages in the world. With regards to her learning strategies, she is aware of the importance of these strategies to faciliate learning.

These excerpts show very different kinds of performance with respect to the use of DMs. Clearly participant $G$ employs a much wider range of DMs than participant $A$. In fact, examination of the entire text reveals that A's repertoire of discourse markers appears to be limited to and, so and because. On the other hand, this excerpt alone shows that G's repertoire of markers is more extensive than A's.

Some learners use certain markers extensively, while others use the same markers rarely if at all. For example, $\mathrm{C}$ used the discourse marker but 5 , times, $\mathrm{B}$ used it only once and the rest of participants never did. Similarly, B and G used the marker therefore 4 and 3 times, respectively, whereas $\mathrm{A}, \mathrm{C}, \mathrm{D}, \mathrm{E}$ and $\mathrm{F}$ never did. The number of DMs used by the participants ranges from 6 (participant A) to 15 (participant C). Participant G used 13 DMs and the rest of participants used $10 \mathrm{DMs}$ each. Each learner used between three and seven different types of markers in their writings. With respect to the type of DMs used, they are the following: 
A) markers that signal a quasi-parallel relationship between two sentences: and (36 times), moreover (once), in particular (once), well (once);

B) markers which signal that sentence 2 is to be taken as a conclusion based on sentence 1: therefore ( 7 times), then (5 times), consequently (once), so (once), hence (once), thus (once);

C) markers that signal that the explicit interpretation of a sentence contrasts with an interpretation of the previous sentence: but ( 6 times), although ( 4 times), however (twice);

D) markers which specify that sentence 2 provides a reason for the content presented in sentence 1 : because ( 8 times), since (once);

E) topic relating discourse marker: with regards to (twice).

A significant point emerges from these observations. The results point to a relationship between the level of competence in writing and the use of markers. Thus, the two essays (C and G) that were written in better English include more markers and the one which showed a weaker command of the English language (A) includes fewer markers and mainly and, so and because.

\section{Pilot study II}

After obtaining the results presented above, we decided to analyse the use of DMs by native speakers of Spanish writing in their mother tongue and then compare the use of DMs in Spanish and in English. We again chose a group of seven people, native speakers of Spanish, whohad studied English in high school and were taking a degree in English Language and Literature at the University of Oviedo. They also had to write an essay on an applied linguistics topic but they did it in Spanish.

We again analysed the section conclusions of their papers. The analysis of the data proceeded in the same way as before. If there were discourse markers, then we determined the range of markers used by each participant. The use of discourse markers by the seven participants was then compared.

\subsection{Results}

We again observed that discourse markers were used extensively and in appropriate ways by participants. They used about the same number of DMs as the participants writing in English (from 7 to 18) although the participants writing in Spanish with the largest number of DMs in their writings used more markers than the same participants writing in English. We also observed that, as it occurs in the previous study, some participants employed a wider range of markers than others. For example, whereas participant $J$ used only three DMs several times, participant $M$ used eight different types of DMs in his writing. 
The types of DMs used by these participants were the same as in the previous study, that is, markers that signal a quasi-parallel relationship between two sentences; markers that signal that sentence 2 is to be taken as a conclusion based on sentence 1 ; markers that signal that the explicit interpretation of a sentence contrasts with an interpretation of the previous sentence; markers which specify that sentence 2 provides a reason for the content presented in sentence 1 and topic relating discourse markers.

However, we observe more variety within the different types of DMs used. Thus, the subjects writing in Spanish used a wider range of markers to express the same relation between the sentences.

\section{Discussion}

This study has shown that native speakers of Spanish use DMs extensively and in appropriate ways both in Spanish and in English. We have observed some differences between the writings in English and Spanish with respect to the number of markers employed as well as the variety of markers used. The results also point to a relationship between the students' level of competence in writing in a foreign language and their use of markers. With these initial results, we may begin to narrow down our research. Our subjects were advanced students of English. We believe that an important question to be considered is what is the range of DMs students use at different proficiency levels. A largescale quantitative study is the only way to make adequate generalisations about groups of learners at different proficiency levels. We need to collect a large amount of data from a large number of individuals. This might involve three or four distinct proficiency levels with several subjects each. Second, a future large-scale study should ask what is the full range of functions of markers used by EFL learners at different levels of proficiency both in the target and mother languages. Finally, it would also be interesting to analyse in depth the relationship between use of DMs and written competence in the foreign language. Of course, all these questions will lead to further, more refined questions, but we believe that at least these questions should be addressed at this early stage.

\section{Notes}

1. The other main approach to DMs is the so-called coherence-based approach. Within coherence theory people assume that texts are coherent, there is a definable set of coherence relations and the recovery of such coherence relations is essential for comprehension. The function of DMs or 'cue phrases' as they call them is to make such coherence relations explicit. Here we will mention the work by Mann and Thompson (1986), Knott and Dale (1994), Sanders, Spooren and Noordman (1993), Fraser (1990) and Hovy and Maier (1994).

Relevance theory and coherence theory take very different views on communication and that has consequences for the analysis of DMs suggested by each of these frameworks. Coherence theorists assume that the most important property of texts is that texts are coherent. Coherence is analyzable in terms of a set of coherence relations, i.e. a set of implicit relations that bind the text 
together. Examples of coherence relations are Cause, Consequence, Condition, etc. Comprehension crucially depends on the recovery of such relations. As we have said, the function of DMs or 'cue phrases' is to make such coherence relations explicit. Within the relevancetheoretic framework, no appeal is made to coherence relations. Rather than attempting to identify such relations, hearers/readers are seen as attempting to determine, for any utterance, how that utterance achieves relevance (see Blakemore 1996: 328).

2. Grice (1975) distinguishes between implicatures -conversational inferences- and conventional implicatures. An implicature is a proposition conveyed implicitly by an utterance. Such propositions are considered implicit in the sense that they are not part of what is 'said', that is, they are not part of the truth-conditional content of the utterance that conveys them. Ordinary conversational implicatures, in the Gricean sense, are implicit propositions which can be inferred from what is said based on pragmatic principles, but a conventional implicature is an implicit proposition which is encoded in a particular linguistic expression rather than inferred. This distinction is taken into account by D. Blakemore (1987:76) for the development of her theory on connectives.

3 . We follow the view of reading within the communicative frame, as a communicative interaction between reader and writer, a communicative act where the reader uses the information in the text to change his cognitive structures (Sinclair, 1981, Widdowson, 1983, Tadros, 1985).

\section{Works cited}

Anscombre, Jean Claude and Oswald Ducrot (1983): L'argumentation dans la Langue. Brussels: Madarga.

Blakemore, Diane (1987): Semantic Constraints on Relevance. Oxford: Blackwell. . (1988): "So as a constraint on relevance". In R. Kempson, ed., Mental representations:

The Interface between Language and Reality. Cambridge: Cambridge University Press, 183-195.

. (1989a): "Denial and contrast: A relevance theoretic analysis of but". Linguistics and Philosophy 12: 28-51.

. (1989b): "Linguistic form and pragmatic interpretation: the explicit and the implicit".

In Leo Hickey, ed., The Pragmatics of Style. London: Routledge.

. (1992): Understanding Utterances. Oxford: Blackwell.

(1993): "The relevance of reformulation". Language and Literature 2(2): 101-220.

(1996): "Are apposition markers discourse markers?". Journal of Linguistics 32:

325-347.

Blass, R. (1990): Relevance Relations in Discourse: A Study with Special Reference to Sissala.

Cambridge: Cambridge University Press.

Ducrot, Oswald (1972): Dire et ne pas Dire. Paris: Hermann.

(1973): La Preuve et le Dire. Paris: Mame.

(1984): Le Dire et le Dit. Paris: Minuit.

Fraser, Bruce (1990) : "An approach to discourse markers". Journal of Pragmatics 14 : 383-395. Grice, H.P. (1975): "Logic and conversation". In P. Cole and J. Morgan, eds., Syntax and

Semantics, Volume 9: Pragmatics. New York: Academic Press.

Halliday, M.A.K. and R. Hasan. (1976): Cohesion in English. London: Longman. 
Hansen, M.B.M. (1997): "Alors and donc in spoken French: A reanalysis". Journal of Pragmatics 28: $153-187$.

Hovy, F. and F. Maier (1994): Parsimonious or Profligate: How Many and Which Discourse Structure Relations? Ms.

Knott, Alistair and R. Dale (1994): "Using linguistic phenomena to motivate a set of coherence relations". Discourse Processes 18: 35-62.

Mann, W. and S. Thompson (1986): "Relational propositions in discourse". Discourse Processes 9: $57-90$.

Sanders, Ted, Spooren, Wilbert and L. Noordman (1993): "Coherence relations in a cognitive theory of discourse representation". Cognitive Linguistics 4(2): 93-133.

Sinclair, J. (1981): 'Planes of discourse'. The Twofold Voice. Essays in Honour of K.Mohan.

Sperber, Dan and Deirdre Wilson (1986): Relevance: Communication and Cognition. Oxford: Blackwell. Second Edition 1995.

. (1995): "Postface". In D. Sperber and D. Wilson. Relevance: Communication and Cognition. Second Edition. Oxford: Blackwell, 255-279.

Tadros, A. (1985): Prediction in Text. Birmingham: English Language Research. University of Birmingham.

Widdowson, H.G. (1983): Learning Purpose and Language Use. Oxford: Oxford University Press.

Wilson, Deirdre and Dan Sperber (1993): "Linguistic form and relevance". Lingua 90:1-25. 